\title{
Endothelium-dependent and-independent relaxation induced by resveratrol in rat superior mesenteric arteries
}

\author{
${\text { YULONG } \mathrm{CHEN}^{1,2}, \mathrm{CANGBAO} \mathrm{XU}^{2,3}, \text { YAHUI WEI }^{4}, \text { YAPING ZHANG }^{2} \text { and AILAN CAO }}^{1,5}$ \\ ${ }^{1}$ Shaanxi Pharmaceutical Development Center, Shaanxi Pharmaceutical Holding Group Co., Ltd., Xi'an, Shaanxi 710075; \\ ${ }^{2}$ Shaanxi Key Laboratory of Ischemic Cardiovascular Disease, Institute of Basic and Translational Medicine, Xi'an \\ Medical University, Xi'an, Shaanxi 710021, P.R. China; ${ }^{3}$ Department of Clinical Sciences, Division of Experimental \\ Vascular Research, Lund University, S-22184 Lund, Sweden; ${ }^{4}$ Key Laboratory of Resource Biology and Biotechnology \\ in Western China, Ministry of Education, College of Life Sciences, Northwest University, Xi'an, Shaanxi 710069; \\ ${ }^{5}$ Preparation Research Room, Shaanxi Chinese Medicine Institute, Xianyang, Shaanxi 712000, P.R. China
}

Received January 15, 2016; Accepted March 2, 2016

DOI: $10.3892 /$ etm.2016.3605

\begin{abstract}
Resveratrol (Res) is a specific agonist of sirtuin 1, and has many cardioprotective effects. Although Res is able to relax various vascular beds, its pharmacological properties in rat superior mesenteric arteries and the underlying mechanism are not well clarified. The aim of present study was to investigate the vasorelaxant effects of Res on rat superior mesenteric arteries and the mechanisms involved. The isometric tension of rat superior mesenteric arterial rings was recorded in vitro using myography. It was found that Res concentration-dependently relaxed endothelium-intact superior mesenteric artery rings pre-contracted by phenylephrine hydrochloride $\left(\mathrm{E}_{\max }, 97.66 \pm 0.79 \% ; \mathrm{pD}_{2}, 4.30 \pm 0.14\right)$ or $\mathrm{KCl}\left(\mathrm{E}_{\max }, 101.3 \pm 0.6 \% ; \mathrm{pD}_{2}, 4.12 \pm 0.03\right)$. The vasorelaxant effect of Res on the superior mesenteric artery rings was partially endothelium-dependent. $\mathrm{N}^{\mathrm{G}}$-nitro-L-arginine methyl ester $(100 \mu \mathrm{M})$ significantly inhibited the Res-induced vasorelaxant effect. However, $1 \mathrm{H}-[1,2,4]$ oxadiazolo[4,3-a] quinoxalin-1-one $(10 \mu \mathrm{M})$ and indomethacin $(5 \mu \mathrm{M})$ each had no effect on the Res-induced vasorelaxation. In artery rings
\end{abstract}

Correspondence to: Professor Ailan Cao, Shaanxi Pharmaceutical Development Center, Shaanxi Pharmaceutical Holding Group Co., Ltd., 69 Keji 2nd Road, Xi'an, Shaanxi 710075, P.R. China

E-mail: caoailan0105@163.com

Abbreviations: PE, phenylephrine hydrochloride; ACh, acetylcholine chloride; 4-AP, 4-aminopyridine; $\mathrm{BaCl} 2$, barium chloride dehydrate; eNOS, endothelial nitric oxide synthase; Gli, glibenclamide; Indo, indomethacin; L-NAME, NG-nitro-L-arginine methyl ester; NO, nitric oxide; ODQ, $1 \mathrm{H}-[1,2,4]$ oxadiazolo[4,3-a] quinoxalin-1-one; ROCC, receptor-operated calcium channel; Res, resveratrol; TEA, tetraethylammonium chloride; VDCC, voltage-dependent calcium channel; vsMCs, vascular smooth muscle cells

Key words: resveratrol, vasorelaxant effects, nitric oxide, $\mathrm{K}^{+}$ channel, $\mathrm{Ca}^{2+}$ influx, superior mesenteric artery without endothelium, the vasorelaxation induced by Res was attenuated by 4 -aminopyridine $(100 \mu \mathrm{M})$ and glibenclamide $(10 \mu \mathrm{M})$. However, barium chloride dehydrate $(10 \mu \mathrm{M})$ and tetraethylammonium chloride $(1 \mathrm{mM})$ did not affect the vasorelaxation induced by Res. Moreover, Res also inhibited the contraction induced by an increase in external calcium concentration in $\mathrm{Ca}^{2+}$-free medium plus $\mathrm{KCl}(60 \mathrm{mM})$. These results suggest that Res induces relaxation in superior mesenteric arterial rings through an endothelium-dependent pathway, involving nitric oxide release, and also through an endothelium-independent pathway, with opening of voltage-dependent $\mathrm{K}^{+}$channels and ATP-sensitive $\mathrm{K}^{+}$channels and blockade of extracellular $\mathrm{Ca}^{2+}$ influx.

\section{Introduction}

Resveratrol (Res) is a natural polyphenolic compound present in grapes and red wine. It is a specific agonist of sirtuin 1 (Sirt1), and has many cardiovascular protective effects, such as anti-inflammatory, anti-oxidative and anti-proliferative effects $(1,2)$.

Previous studies have shown that Res is able to relax vascular beds of various types, including conductance arteries, such as the uterine artery (3), aorta (4-6), abdominal aorta (7) and thoracic aorta (8), and resistance arteries, such as the internal mammary artery (9), mesenteric artery $(3,10,11)$ and coronary artery (12). The vasorelaxant effects of Res on conductance arteries and the underlying mechanism have been well clarified. However, the vasodilatation and vasodilatory mechanisms in small resistance arteries are associated with cardiovascular events (13). Although Res possesses the pharmacological property of vasodilatation in resistance arteries, several pathways involved in the mechanism of vasodilatation are unclear.

Therefore, the present study was designed to explore the mechanism by which Res induces vasodilatation in rat superior mesenteric arteries. This should further reveal the underlying mechanisms involved in the vasorelaxant effect of Res on resistance arteries, and provide a theoretical basis for the development of cardiovascular drugs. 


\section{Materials and methods}

Reagents. Phenylephrine hydrochloride (PE), acetylcholine chloride (ACh), $\mathrm{N}^{\mathrm{G}}$-nitro-L-arginine methyl ester (L-NAME), $1 \mathrm{H}$-[1,2,4]oxadiazolo[4,3-a]quinoxalin-1-one (ODQ), indomethacin (Indo), 4-aminopyridine (4-AP), barium chloride dehydrate $\left(\mathrm{BaCl}_{2}\right)$, glibenclamide (Gli), tetraethylammonium chloride (TEA) and Triton X-100 were obtained from Sigma-Aldrich (St. Louis, MO, USA). Res was obtained from the College of Life Science, Northwest University (Xi'an, China). ODQ, TEA, Gli, 4-AP, and Res were dissolved in dimethylsulfoxide. All other compounds were dissolved in distilled water.

Artery preparation and testing. Thirty male Sprague-Dawley rats (8 weeks old; body weight, 300-350 g), which were obtained from the Animal Center of Xi'an Jiaotong University (Xi'an, China), were euthanized with $\mathrm{CO}_{2}$. The superior mesenteric artery was gently removed and freed from adhering tissue under a dissecting microscope. The animal experiments in this study were approved by the Laboratory Animal Administration Committee of Xi'an Medical University (Xi'an, China) and performed according to the Guidelines for Animal Experimentation of Xi'an Medical University and the Guide for the Care and Use of Laboratory Animals published by the US National Institutes of Health (NIH Publication No. 85-23, revised 1996).

Triton X-100 is a non-ionic detergent. It directly dissolves the lipid bilayer in endothelial cell membranes to cause destruction of endothelial cell surfaces. In this study, the endothelium was denuded by perfusion of the vessel for $10 \mathrm{sec}$ with X-100 $(0.1 \%, \mathrm{v} / \mathrm{v})$ followed by another $10 \mathrm{sec}$ with a physiological buffer solution (PSS; $\mathrm{NaCl} 119 \mathrm{mM}, \mathrm{KCl} 4.6 \mathrm{mM}, \mathrm{NaHCO}_{3}$ $15 \mathrm{mM}, \mathrm{NaH}_{2} \mathrm{PO}_{4} 1.2 \mathrm{mM}, \mathrm{MgCl}_{2} 1.2 \mathrm{mM}, \mathrm{CaCl}_{2} 1.5 \mathrm{mM}$ and glucose $5.5 \mathrm{mM}$ ). The vessels were then cut into 1-3-mm long cylindrical segments.

The segments, with and without endothelium, were immersed in individual temperature-controlled $\left(37^{\circ} \mathrm{C}\right)$ myograph baths (Organ Bath Model 700MO; J.P. Trading, Aarhus, Denmark) containing PSS ( $5 \mathrm{ml})$. The solution was continuously aerated with gas comprising $5 \% \mathrm{CO}_{2}$ and $95 \% \mathrm{O}_{2}$, resulting in a $\mathrm{pH}$ of 7.4. The arterial segments were mounted for continuous recording of isometric tension using LabChart 7 Pro software (ADInstruments, Hastings, UK). A resting tone of $2 \mathrm{mN}$ was applied to each segment, and the segments were allowed to stabilize at this tension for at $\geq 1.5 \mathrm{~h}$ prior to exposure to $\mathrm{K}^{+}$-rich (60 $\mathrm{mM}$ ) buffer solution with the same composition as the standard solution, with the exception that $\mathrm{NaCl}$ was replaced by an equimolar concentration of $\mathrm{KCl}$ (KPSS). The potassium-induced contraction was used as a reference for contractile capacity, and the segments were used only if potassium elicited reproducible responses $>1.0 \mathrm{mN}$. Following equilibration, $\mathrm{PE}$ $(10 \mu \mathrm{M})$ or KPSS (containing $60 \mathrm{mM} \mathrm{K}^{+}$) was added to the bath. When a sustained tension was obtained, Res $\left(5 \times 10^{-7}-5 \times 10^{-4} \mathrm{M}\right)$ was added cumulatively to the baths and concentration-response curves to Res were constructed. After the experiment, the bath was washed with PSS three times. PE $(10 \mu \mathrm{M})$ or KPSS was added to the bath again following equilibration. The difference in contractile capacity between before and after the experiment was used as a reference for the toxicity of Res.
With regard to the endothelium, the completeness of endothelium denudation was tested with ACh $(10 \mu \mathrm{M})$ following pre-contraction with KPSS. No relaxation in response to $\mathrm{ACh}$ in the denuded preparation indicated an effective functional removal of the endothelium. Endothelium-intact rings that produced $<30 \%$ relaxation in response to $\mathrm{ACh}$ were discarded (14).

In vitro pharmacology. To evaluate the effects of Res on the contraction induced by $\mathrm{PE}$ or $\mathrm{KCl}$, superior mesenteric artery rings were pre-contracted with $\mathrm{PE}(10 \mu \mathrm{M})$ or $\mathrm{KCl}(60 \mathrm{mM})$, and once a plateau was attained, concentration-response curves were obtained by adding cumulative doses of Res to the bath.

To identify the endothelial mediator (s) associated with the vasodilatory effect of Res, an endothelial nitric oxide synthase (eNOS) inhibitor [L-NAME $(100 \mu \mathrm{M})]$, a guanylate cyclase inhibitor [ODQ $(10 \mu \mathrm{M})$ ] and a cyclooxygenase inhibitor [Indo $(5 \mu \mathrm{M})]$ were used. The endothelium-intact artery rings were pre-incubated with each of these inhibitors for $20 \mathrm{~min}$ before $\mathrm{KCl}(60 \mathrm{mM})$ was added to the bath, and then Res was added cumulatively.

In order to demonstrate the role of $\mathrm{K}^{+}$channels in Res-induced relaxation, artery rings without endothelium were pre-incubated with the $\mathrm{K}^{+}$channel blockers 4-AP $(100 \mu \mathrm{M})$, $\mathrm{BaCl}_{2}(10 \mu \mathrm{M})$, Gli $(10 \mu \mathrm{M})$ and TEA $(1 \mathrm{mM})$, independently, for $20 \mathrm{~min}$ before $\mathrm{KCl}(60 \mathrm{mM})$ was added, and then Res was added cumulatively.

To clarify whether the relaxation induced by Res was associated with intracellular $\mathrm{Ca}^{2+}$ release, experiments were carried out in $\mathrm{Ca}^{2+}$-free PSS $(100 \mu \mathrm{M})$. Rings without endothelium were washed with $\mathrm{Ca}^{2+}$-free PSS. Following incubation with or without Res $(500 \mu \mathrm{M})$ for $20 \mathrm{~min}, \mathrm{PE}(10 \mu \mathrm{M})$ was added to stimulate the release of intracellular $\mathrm{Ca}^{2+}$ and the contraction was recorded (15).

Finally, to determine whether the inhibition of extracellular $\mathrm{Ca}^{2+}$ influx was involved in the relaxation induced by Res, experiments were carried out in $\mathrm{Ca}^{2+}$-free PSS $(100 \mu \mathrm{M})$. Artery rings without endothelium were washed with $\mathrm{Ca}^{2+}$-free PSS containing ethylene glycol tetraacetic acid (EGTA; $100 \mu \mathrm{M}$ ) and then rinsed with $\mathrm{Ca}^{2+}$-free PSS (without EGTA) containing $\mathrm{KCl}\left(60 \mathrm{mM} \mathrm{K}^{+}\right)$. Following incubation with or without Res $(500 \mu \mathrm{M})$ for $20 \mathrm{~min}, \mathrm{CaCl}_{2}(2 \mathrm{mM})$ was added to contract the artery rings (15).

Statistical analysis. Data are expressed as mean \pm standard error of the mean. The effects of Res are expressed as percentage of relaxation from the pre-contraction. The negative logarithm of the dilator concentration that caused $50 \%$ of the maximum response $\left(\mathrm{pD}_{2}\right)$ and the maximum relaxation $(\mathrm{Emax} \%)$ were calculated. Statistical analysis was performed with unpaired Student's $t$-test. $\mathrm{P}<0.05$ was considered to indicate a statistically significant result. The analysis was performed using SPSS software, version 16.0 (SPSS Inc., Chicago, IL, USA).

\section{Results}

Effect of Res on rat superior mesenteric artery pre-constricted by $\mathrm{PE}$ or $\mathrm{KCl}$. Res $(0.5-500 \mu \mathrm{M})$ concentration-dependently relaxed the endothelium-intact superior mesenteric artery rings pre-contracted by $\mathrm{PE}\left(\mathrm{E}_{\max }, 97.66 \pm 0.79 \% ; \mathrm{pD}_{2}, 4.30 \pm 0.14\right)$ or 

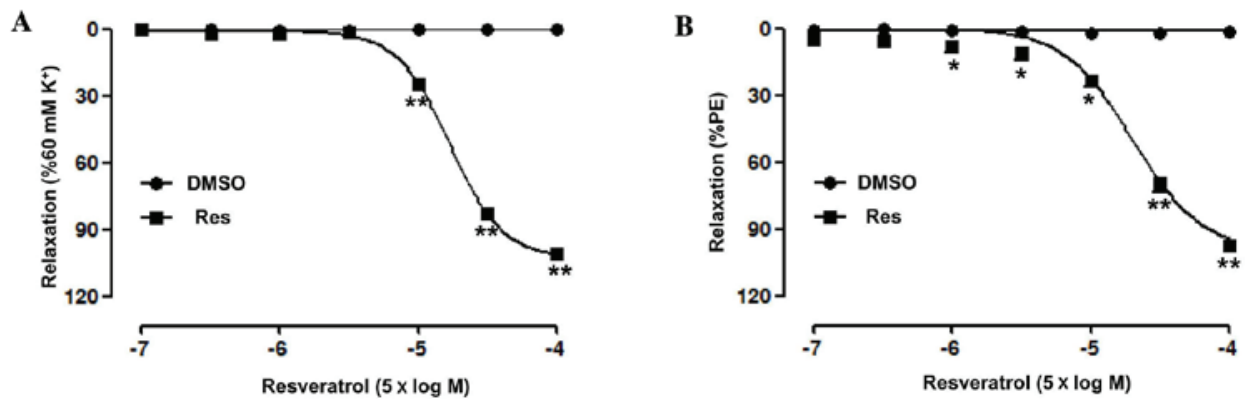

Figure 1. Vasodilatation effects of resveratrol on endothelium-intact superior mesenteric arterial rings pre-contracted with (A) $\mathrm{KCl}(60 \mathrm{mM})$ or (B) $\mathrm{PE}(10 \mu \mathrm{M})$. Data are presented as mean \pm standard error of the mean $(n=6-8)$. ${ }^{*} \mathrm{P}<0.05$ and ${ }^{* *} \mathrm{P}<0.01$ vs. DMSO. PE, phenylephrine hydrochloride; DMSO, dimethylsulfoxide.

$\mathrm{KCl}\left(\mathrm{E}_{\max }, 101.3 \pm 0.6 \% ; \mathrm{pD}_{2}, 4.12 \pm 0.03\right)$ (Fig. 1). In addition, there was no significant change in the contractile capacity of the superior mesenteric artery induced by PE or KPSS between before and after the experiment, suggesting that Res has no toxicity.

Role of the endothelium in Res-induce relaxation of rat superior mesenteric artery pre-constricted by $\mathrm{KCl}$. The vasorelaxant effect of Res on endothelium-intact superior mesenteric artery rings pre-contracted by $\mathrm{PE}(10 \mu \mathrm{M})$ was significantly stronger than that on artery rings without endothelium, with an $\mathrm{E}_{\max }$ of $97.69 \pm 0.82$ vs. $89.72 \pm 0.1 .89 \%$ for the artery rings without endothelium group, and $\mathrm{ap}_{2}$ of $4.31 \pm 0.14$ vs. $3.86 \pm 0.04$ for the artery rings without endothelium group. Moreover, the vasorelaxation induced by Res in endothelium-intact artery rings pre-contracted by $\mathrm{KCl}(60 \mathrm{mM})$ also was significantly stronger than that in artery rings without endothelium, with an $\mathrm{E}_{\max }$ of $100.94 \pm 0.59$ vs. $95.63 \pm 0.63 \%$ for the artery rings without endothelium group and $\mathrm{a}_{2}$ of $4.13 \pm 0.03$ vs. $4.09 \pm 0.01$ for the artery rings without endothelium group ( $\mathrm{P}<0.05$; Fig. 2 ).

The endothelial mediator(s) associated with the vasodilatory effect of Res were investigated by pre-incubation with the eNOS inhibitor L-NAME, guanylate cyclase inhibitor ODQ and cyclooxygenase inhibitor Indo, independently, prior to treatment with $\mathrm{KCl}$ or Res. The results showed that L-NAME significantly inhibited the relaxation induced by Res in the artery rings with endothelium, with an $\mathrm{E}_{\max }$ of $89.93 \pm 0.17$ vs. $100.96 \pm 0.76 \%$ in the control group, and $\mathrm{aD}_{2}$ of $3.91 \pm 0.03$ vs. $4.15 \pm 0.02$ in the control group $(\mathrm{P}<0.05$; Fig. $3 \mathrm{~A})$. However, ODQ and Indo each did not significantly affect the relaxation induced by Res in the artery rings with endothelium (Fig. 3B and C).

Role of $\mathrm{K}^{+}$channels in the Res-induced relaxation of rat superior mesenteric artery pre-constricted by $\mathrm{KCl}$. Artery rings without endothelium were pre-incubated with the $\mathrm{K}^{+}$ channel blockers 4-AP, $\mathrm{BaCl}_{2}$, Gli and TEA, independently, prior to treatment with $\mathrm{KCl}$ and Res in order to investigate the role of $\mathrm{K}^{+}$channels in the Res-induced relaxation. The results showed that 4-AP significantly reduced the relaxation induced by Res in the artery rings without endothelium, with an $\mathrm{E}_{\max }$ of $90.15 \pm 1.6$ vs. $96.38 \pm 0.44 \%$ in the control group and $\mathrm{pD}_{2}$ of $3.94 \pm 0.03$ vs. $4.1 \pm 0.02$ in the control group $(\mathrm{P}<0.05$; Fig. 4A). However, $\mathrm{BaCl}_{2}$ did not significantly affect the relaxation induced by Res in the artery rings without endothelium (Fig. 4B). In addition, Gli also significantly reduced the relaxation induced by Res in the artery rings without endothelium, with an $\mathrm{E}_{\max }$ of $89.75 \pm 1.24$ vs. $95.82 \pm 0.49 \%$ in the control group and $\mathrm{pD}_{2}$ of $3.86 \pm 0.05$ vs. $4.07 \pm 0.02$ in the control group ( $\mathrm{P}<0.05$; Fig. 4C), whilst TEA, similar to $\mathrm{BaCl}_{2}$, did not significantly affect the relaxation induced by Res in the artery rings without endothelium (Fig. 4D).

Effect of Res on calcium release by the sarcoplasmic reticulum in rat superior mesenteric artery pre-constricted by $P E$. Experiments were carried out in $\mathrm{Ca}^{2+}$-free buffer to clarify whether the relaxation induced by Res was associated with intracellular $\mathrm{Ca}^{2+}$ release. The results showed that PE induced a transient contraction due to the release of intracellular $\mathrm{Ca}^{2+}$ in the $\mathrm{Ca}^{2+}$-free solution, with an $\mathrm{E}_{\max }$ of $6.35 \pm 1.5 \%$. Res attenuated the contraction induced by $\mathrm{PE}$, with an $\mathrm{E}_{\max }$ of $3.85 \pm 0.95 \%$; however, the difference was not significant (Fig. 5A).

Effect of Res on extracellular $\mathrm{Ca}^{2+}$-induced contraction in rat superior mesenteric artery pre-constricted by $\mathrm{KCl}$. Experiments were carried out in $\mathrm{Ca}^{2+}$-free buffer to determine whether the inhibition of extracellular $\mathrm{Ca}^{2+}$ influx is involved in the Res-induced relaxation of artery rings without endothelium. The results showed that Res significantly attenuated $\mathrm{CaCl}_{2}$-induced contraction in the $\mathrm{Ca}^{2+}$-free PSS containing $\mathrm{KCl}\left(60 \mathrm{mM} \mathrm{K}^{+}\right)$, with an $\mathrm{E}_{\max }$ of $3.6 \pm 0.31$ vs. $101.4 \pm 1.79 \%$ in the control group $(\mathrm{P}<0.01$; Fig. $5 \mathrm{~B})$. This suggests that $\mathrm{Ca}^{2+}$ influx was inhibited by Res in the superior mesenteric artery.

\section{Discussion}

The present study found that Res concentration-dependently relaxed superior mesenteric artery rings with or without endothelium that had been pre-contracted using $\mathrm{PE}$ or $\mathrm{KCl}$. This suggests that Res induced vasorelaxation via endothelium-dependent and-independent pathways. Moreover, the vasorelaxation induced by Res was inhibited by L-NAME, and not affected by ODQ or Indo in artery rings with endothelium. In addition, the vasorelaxation induced by Res was inhibited by $4-\mathrm{AP}$ and Gli, and not affected by $\mathrm{BaCl}_{2}$ and TEA in artery rings without endothelium. Finally, it was also found that the vasorelaxation induced by Res was mediated through blockade of $\mathrm{Ca}^{2+}$ influx from extracellular medium.

Vascular endothelium, occupying a location between circulating blood and vascular smooth muscle, is considered to be 

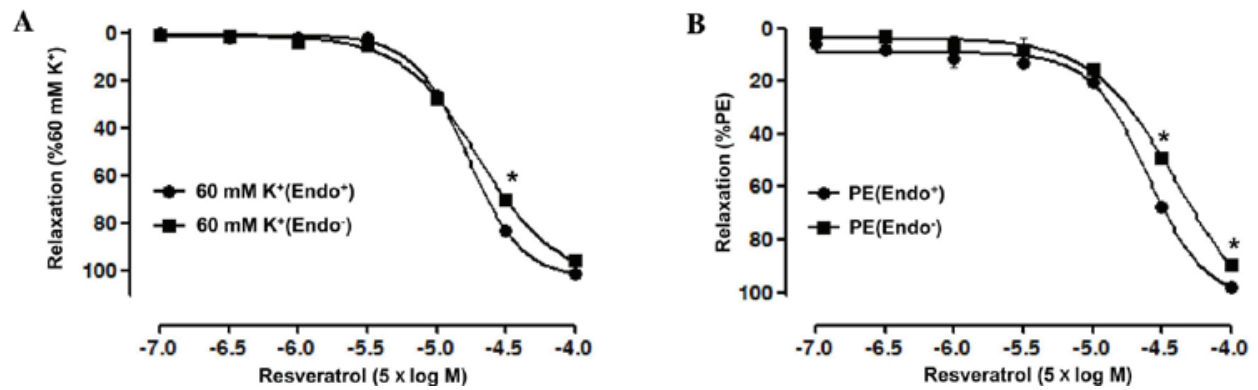

Figure 2. Vasodilatation effects of resveratrol on endothelium-intact and endothelium-denuded superior mesenteric arterial rings pre-contracted with (A) $\mathrm{KCl}(60 \mathrm{mM})$ or $(\mathrm{B}) \mathrm{PE}(10 \mu \mathrm{M})$. Data are presented as mean \pm standard error of the mean $(\mathrm{n}=6-8)$. "P<0.05 for Endo+ vs. Endo-. Endo+, artery ring with endothelium; Endo-, artery ring without endothelium. PE, phenylephrine hydrochloride.

A

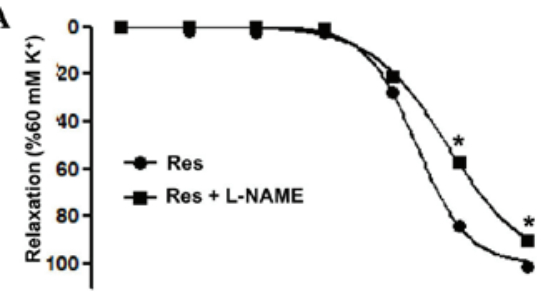

B

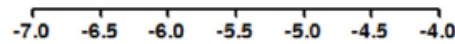

B'
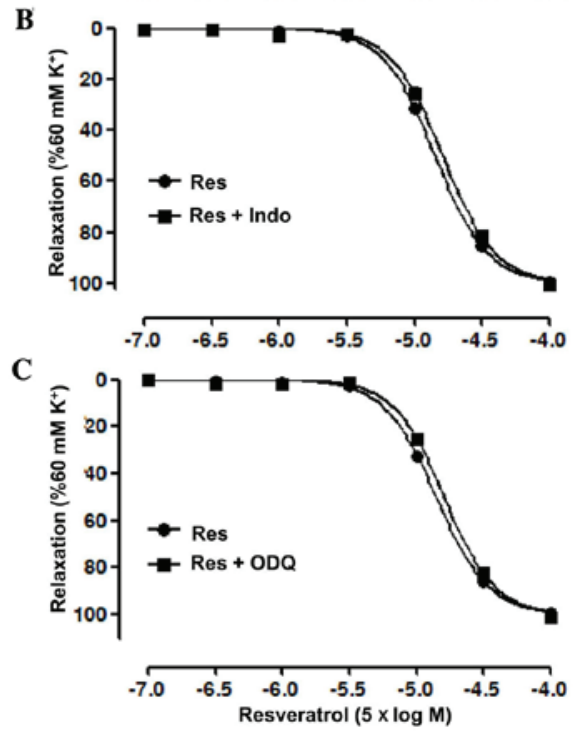

Figure 3. Vasodilatation effects of resveratrol (Res) on endothelium-intact superior mesenteric arterial rings pre-contracted with $\mathrm{KCl}(60 \mathrm{mM})$ in the presence of (A) the endothelial nitric oxide synthase inhibitor (L-NAME, $100 \mu \mathrm{M}$ ), (B) the cyclooxygenase inhibitor (Indo, $5 \mu \mathrm{M}$ ) and (C) the guanylate cyclase inhibitor (ODQ, $10 \mu \mathrm{M})$. Data are presented as mean \pm standard error of the mean ( $n=6-8)$. ${ }^{*} \mathrm{P}<0.05$ vs. Res. L-NAME, $\mathrm{N}^{\mathrm{G}}$-nitro-L-arginine methyl ester; Indo, indomethacin; ODQ, 1H-[1,2,4]oxadiazolo[4,3-a]quinoxalin-1-one.

important in the regulation of vascular tone. The vasorelaxation is mediated by relaxing substances synthesized in and released by the endothelium (16). In the present study, the relaxant effect induced by Res was attenuated in the superior mesenteric artery rings without endothelium, suggesting that Res relaxed the artery through an endothelium-dependent pathway. The data showed that L-NAME (an eNOS inhibitor) significantly reduced the vasorelaxation induced by Res. However, Indo (a cyclooxygenase inhibitor) and ODQ (a guanylate cyclase inhibitor) did not affect the action of Res. This suggests that nitric oxide (NO) is involved in the relaxation of Res in the superior mesenteric artery with endothelium, whereas the cGMP pathway and prostanoids are not associated with this effect. This finding is consistent with previous studies; in the abdominal aorta, thoracic aorta and coronary artery, the efficacy of Res has been found to be closely associated with the NO system in endothelial cells $(4,7,8,12)$.

In the present study, it was found that Res also induced a relaxant effect in superior mesenteric artery without endothelium, suggesting that Res has a direct effect on vascular smooth muscle cells (VSMCs). The opening of $\mathrm{K}^{+}$channels in vsMCs causes membrane potential hyperpolarization, decreases $\mathrm{Ca}^{2+}$ entry through voltage-operated $\mathrm{Ca}^{2+}$ channels, and induces vasorelaxation $(17,18)$. Several types of $\mathrm{K}^{+}$channels have been identified in vascular smooth muscle. The most abundant types include large conductance $\mathrm{Ca}^{2+}$-activated $\mathrm{K}^{+}$channels, voltage sensitive $\mathrm{K}^{+}$channels, ATP-sensitive $\mathrm{K}^{+}$channels and inward rectifying potassium channels (19). In order to detect the contribution of different types of $\mathrm{K}^{+}$channels to the endothelium-independent relaxation induced by Res in superior mesenteric artery rings, agents that are known to possess $\mathrm{K}^{+}$ channel-blocking activity, namely 4-AP (a voltage-dependent $\mathrm{K}^{+}$channel blocker), $\mathrm{BaCl}_{2}$ (an inward rectifying potassium channel blocker), Gli (an ATP-sensitive $\mathrm{K}^{+}$channel blocker) and TEA (a Ca ${ }^{2+}$-activated $\mathrm{K}^{+}$channel blocker) $(20,21)$ were used.

Previous studies have found that Res relaxes many types of vascular beds without endothelium through the activation of different types of $\mathrm{K}^{+}$channels. The voltage-dependent $\mathrm{K}^{+}$ channel plays an important role in the vasodilatation induced by Res in the aorta (6) and internal mammary artery (9), whereas, the voltage-dependent $\mathrm{K}^{+}$channel is involved in the vasodilatation induced by Res in the thoracic aorta (6). In addition, Res has been shown to induce relaxation of the abdominal aorta through activation of ATP-sensitive $\mathrm{K}^{+}$channels and $\mathrm{Ca}^{2+}$-activated $\mathrm{K}^{+}$channels (7). However, Gojkovic-Bukarica et al found that $\mathrm{K}^{+}$channel-independent mechanisms are involved in its vasorelaxant effect in mesenteric arteries (10). In the present study, both 4-AP and Gli significantly inhibited the relaxant effect of Res, indicating that voltage-dependent $\mathrm{K}^{+}$channels and ATP-sensitive $\mathrm{K}^{+}$channels are involved in the relaxation of the superior mesenteric artery induced by Res. However, neither $\mathrm{BaCl}_{2}$ nor TEA affected the concentration-response curves of Res, suggesting that inward rectifying $\mathrm{K}^{+}$channels and $\mathrm{Ca}^{2+}$-activated $\mathrm{K}^{+}$channels are not involved in the Res-induced relaxation. 

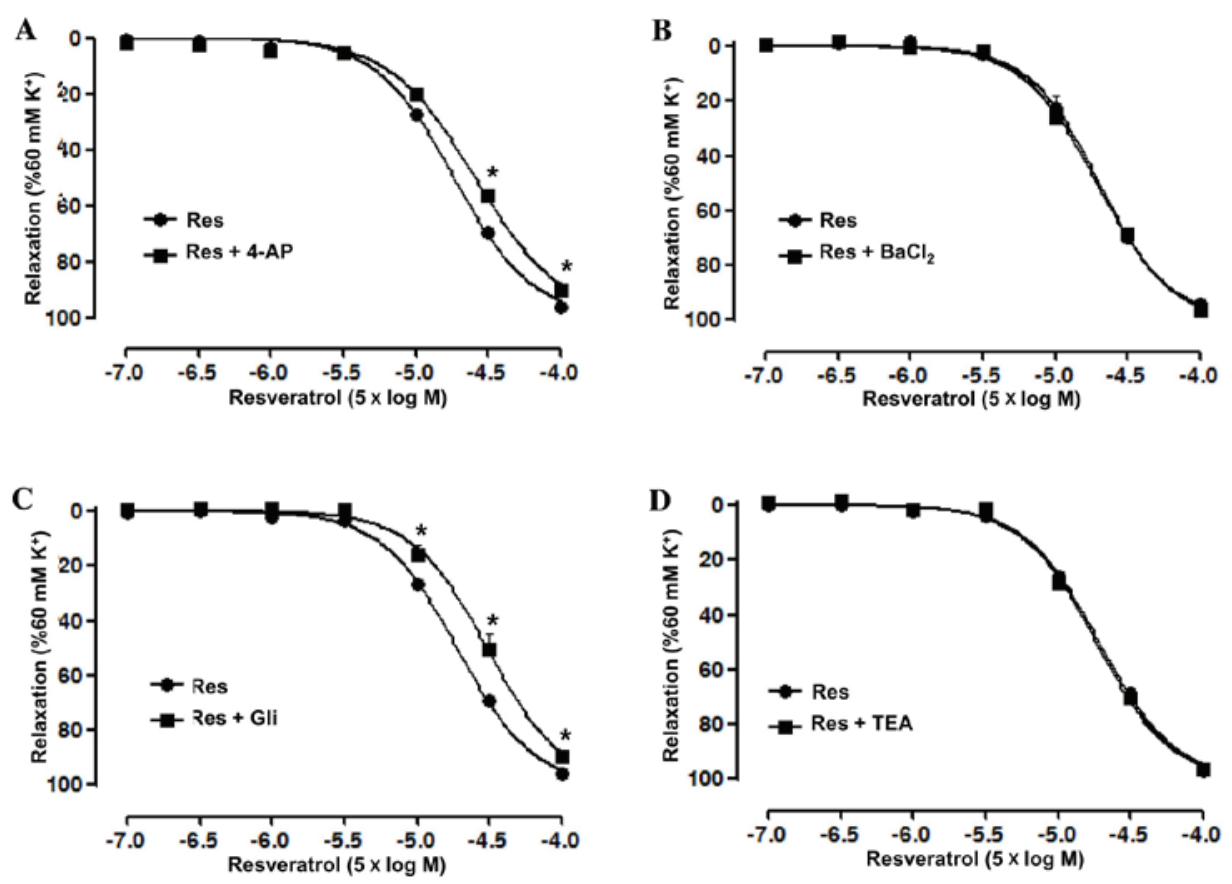

Figure 4. Vasodilatation effects of resveratrol (Res) on endothelium-denuded superior mesenteric arterial rings pre-contracted with $\mathrm{KCl}(60 \mathrm{mM})$ in the presence of the $\mathrm{K}^{+}$channel blockers (A) 4-aminopyridine (4-AP; $\left.100 \mu \mathrm{M}\right)$, (B) barium chloride dehydrate $\left(\mathrm{BaCl}_{2}, 10 \mu \mathrm{M}\right)$, (C) glibenclamide (Gli; $\left.10 \mu \mathrm{M}\right)$ and (D) tetraethylammonium chloride (TEA; $1 \mathrm{mM})$. Data are presented as mean \pm standard error of the mean $(\mathrm{n}=6-8) .{ }^{*} \mathrm{P}<0.05$.
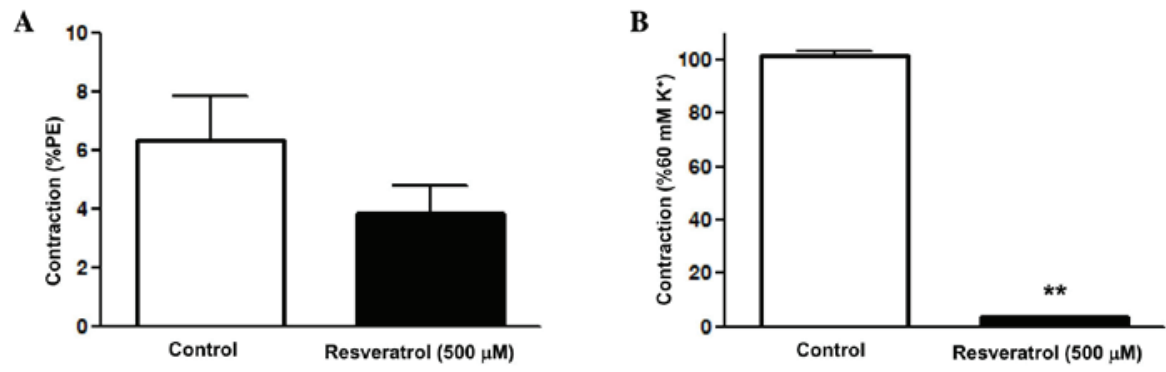

Figure 5. Inhibitory effect of resveratrol on (A) intracellular $\mathrm{Ca}^{2+}$ release induced by $\mathrm{PE}(10 \mu \mathrm{M})$ and (B) extracellular $\mathrm{Ca}^{2+}$ influx induced by $\mathrm{KCl}(60 \mathrm{mM})$ in $\mathrm{Ca}^{2+}$-free solution in endothelium-denuded superior mesenteric arterial rings. Data are presented as mean \pm standard error of the mean $(\mathrm{n}=6-8) .{ }^{* *} \mathrm{P}<0.01$ vs. control. PE, phenylephrine hydrochloride.

Accumulation of intracellular calcium is involved in vascular smooth muscle contraction. Moreover, both extracellular $\mathrm{Ca}^{2+}$ influx, through voltage-dependent calcium channels (VDCCs) or receptor-operated calcium channel (ROCCs), and intracellular $\mathrm{Ca}^{2+}$ release result in an increase of the intracellular calcium level (22). Contractions of vsMCs induced by $\mathrm{KCl}$ rely almost exclusively on $\mathrm{Ca}^{2+}$ influx induced by the activation of voltage-sensitive channels (23), whereas contractions induced by PE are mediated by an increase in $\mathrm{Ca}^{2+}$ influx through both receptor-operated channels (24) and voltage-sensitive channels (25). The results of the present study show that Res is able to inhibit the contractile effects induced by $\mathrm{PE}$ or $\mathrm{KCl}$ on the superior mesenteric artery without endothelium. This suggests that Res may exert effects on both VDCCs and ROCCs. The release of intracellular stored $\mathrm{Ca}^{2+}$ is mainly regulated by the inositol trisphosphate (IP3) receptor system and the ryanodine receptor system (26). Contractions induced by $\mathrm{PE}$ in $\mathrm{Ca}^{2+}$-free medium occur due to intracellular $\mathrm{Ca}^{2+}$ release through $\mathrm{Ca}^{2+}$ channels in the sarcoplasmic reticulum activated by IP3 (27). Previous studies have shown that Res attenuates extracellular calcium influx and intracellular calcium release, which results in vasodilatation in the abdominal aorta (7) or thoracic aorta (8). However, Res has $\mathrm{Ca}^{2+}$ antagonistic properties and inhibits extracellular $\mathrm{Ca}^{2+}$ influx through VDCCs in coronary arteries (12). In the present study, it was found that Res significantly inhibited $\mathrm{CaCl}_{2}$-induced contraction in the superior mesenteric artery rings without endothelium in $\mathrm{Ca}^{2+}$-free PSS containing $\mathrm{KCl}$ $(60 \mathrm{mM})$, indicating that Res exhibits $\mathrm{Ca}^{2+}$ entry blocking activity. However, Res did not inhibit the contraction triggered by PE in $\mathrm{Ca}^{2+}$-free PSS, suggesting that Res does not inhibit $\mathrm{Ca}^{2+}$ mobilization from intracellular stores. In the superior mesenteric artery, it appears that Res induced vasorelaxation via the inhibition of extracellular calcium in vsMCs.

In conclusion, the results of the present study suggest that Res-induced relaxation of the rat superior mesenteric artery occurs via an endothelium-dependent pathway involving NO release, as well as an endothelium-independent pathway, with 
opening of voltage-dependent $\mathrm{K}^{+}$channels and ATP-sensitive $\mathrm{K}^{+}$channels, and blockade of extracellular $\mathrm{Ca}^{2+}$ influx.

\section{Acknowledgements}

This study was supported by the National Natural Science Foundation of China (grant no. 81500350) and China Postdoctoral Science Foundation (grant no. 2015M582607).

\section{References}

1. Koo SH and Montminy M: In vino veritas: A tale of two sirt1s? Cell 127: 1091-1093, 2006.

2. Wang H, Yang YJ, Qian HY, Zhang Q, Xu H and Li JJ: Resveratrol in cardiovascular disease: What is known from current research? Heart Fail Rev 17: 437-448, 2012.

3. Naderali EK, Doyle PJ and Williams G: Resveratrol induces vasorelaxation of mesenteric and uterine arteries from female guinea-pigs. Clin Sci (Lond) 98: 537-543, 2000.

4. Soylemez S, Gurdal H, Sepici A and Akar F: The effect of long-term resveratrol treatment on relaxation to estrogen in aortae from male and female rats: Role of nitric oxide and superoxide. Vascul Pharmacol 49: 97-105, 2008.

5. Taguchi K, Hida M, Matsumoto T and Kobayashi T: Resveratrol ameliorates clonidine-induced endothelium-dependent relaxation involving Akt and endothelial nitric oxide synthase regulation in type 2 diabetic mice. Biol Pharm Bull 38: 1864-1872, 2015.

6. Novakovic A, Bukarica LG, Kanjuh V and Heinle H: Potassium channels-mediated vasorelaxation of rat aorta induced by resveratrol. Basic Clin Pharmacol Toxicol 99: 360-364, 2006.

7. Shen M, Zhao L, Wu RX, Yue SQ and Pei JM: The vasorelaxing effect of resveratrol on abdominal aorta from rats and its underlying mechanisms. Vascul Pharmacol 58: 64-70, 2013.

8. Zhang HY, Xu CQ, Li HZ, Li BX, Zhang YQ and Zhang YN Effects of resveratrol on isolated thoracic aorta rings of rats. Zhongguo Zhong Yao Za Zhi 30: 1283-1286, 2005 (In Chinese).

9. Novakovic A, Gojkovic-Bukarica L, Peric M, Nezic D, Djukanovic B, Markovic-Lipkovski J and Heinle H: The mechanism of endothelium-independent relaxation induced by the wine polyphenol resveratrol in human internal mammary artery. J Pharmacol Sci 101: 85-90, 2006.

10. Gojkovic-Bukarica L, Novakovic A, Kanjuh V, Bumbasirevic M, Lesic A and Heinle $\mathrm{H}$ : A role of ion channels in the endothelium-independent relaxation of rat mesenteric artery induced by resveratrol. J Pharmacol Sci 108: 124-130, 2008.

11. Naderali EK, Smith SL, Doyle PJ and Williams G: The mechanism of resveratrol-induced vasorelaxation differs in the mesenteric resistance arteries of lean andobese rats. Clin Sci (Lond) 100: 55-60, 2001.

12. Li HF, Tian ZF, Qiu XQ, Wu JX, Zhang P and Jia ZJ: A study of mechanisms involved in vasodilatation induced by resveratrol in isolated porcine coronary artery. Physiol Res 55: 365-372, 2006.
13. Mathiassen ON, Buus NH, Sihm I, Thybo NK, Mørn B, Schroeder AP, Thygesen K, Aalkjaer C, Lederballe O, Mulvany MJ and Christensen KL: Small artery structure is an independent predictor of cardiovascular events in essential hypertension. J Hypertens 25: 1021-1026, 2007.

14. Cao YX, Zhang W, He JY, He LC and Xu CB: Ligustilide induces vasodilatation via inhibiting voltage dependent calcium channel and receptor-mediated $\mathrm{Ca}^{2+}$ influx and release. Vascul Pharmacol 45: 171-176, 2006.

15. Zhu XM, Fang LH, Li YJ and Du GH: Endothelium-dependent and -independent relaxation induced by pinocembrin in rat aortic rings. Vascul Pharmacol 46: 160-165, 2007.

16. Rubanyi GM: The role of endothelium in cardiovascular homeostasis and diseases. J Cardiovasc Pharmacol 22 (Suppl 4): S1-S14, 1993.

17. Nelson MT and Quayle JM: Physiological roles and properties of potassium channels in arterial smooth muscle. Am J Physiol 268: C799-C822, 1995.

18. Bolotina VM, Najibi S, Palacino JJ, Pagano PJ and Cohen RA: Nitric oxide directly activates calcium-dependent potassium channels in vascular smooth muscle. Nature 368: 850-853, 1994.

19. Jackson WF: Potassium channelsin the peripheral microcirculation. Microcirculation 12: 113-127, 2005.

20. Brayden JE: Potassium channels in vascular smooth muscle. Clin Exp Pharmacol Physiol 23: 1069-1076, 1996.

21. Vergara C, Latorre R, Marrion NV and Adelman JP: Calcium-activated potassium channels. Curr Opin Neurobiol 8: 321-329, 1998.

22. Horowitz A, Menice CB, Laporte R and Morgan KG: Mechanisms of smooth muscle contraction. Physiol Rev 76: 967-1003, 1996.

23. Hirata S, Enoki T, Kitamura R, Vinh VH, Nakamura K and Mori K: Effects of isoflurane on receptor-operated $\mathrm{Ca}^{2+}$ channels in rat aortic smooth muscle. Br J Anaesth 81: 578-583, 1998 .

24. Lee CH, Poburko D, Sahota P, Sandhu J, Ruehlmann DO and van Breemen $C$ : The mechanism of phenylephrine-mediated $[\mathrm{Ca}(2+)](\mathrm{i})$ oscillations underlying tonic contraction in the rabbit inferior vena cava. J Physiol 534: 641-650, 2001.

25. Lee CN, Wong KL, Liu JC, Chen YJ, Cheng JT and Chan P: Inhibitory effect of stevioside on calcium influx to produce antihypertension. Planta Med 67: 796-799, 2001.

26. Tanaka Y and Tashjian AH Jr: Thimerosal potentiates Ca2+ release mediated by both the inositol 1,4,5-trisphosphate and the ryanodine receptors in sea urchin eggs. Implications for mechanistic studies on $\mathrm{Ca}^{2+}$ signaling. J Biol Chem 269: 11247-11253, 1994.

27. Eckert RE, Karsten AJ, Utz J and Ziegler M: Regulation of renal artery smooth muscle tone by alpha1-adrenoceptors: Role of voltage-gated calcium channels and intracellular calcium stores. Urol Res 28: 122-127, 2000. 